\title{
BMJ Open Assessment of serological techniques for screening patients for COVID-19 (COVID-SER): a prospective, multicentric study
}

\author{
Sophie Trouillet-Assant, ${ }^{1,2}$ Chloe Albert Vega (D) , ${ }^{2}$ Antonin Bal, ${ }^{1,3}$ \\ Julie Anne Nazare, ${ }^{4}$ Pascal Fascia, ${ }^{5}$ Adèle Paul, ${ }^{6,7}$ Amélie Massardier-Pilonchery, ${ }^{6,7}$ \\ Constance d Aubarede, ${ }^{7}$ Nicolas Guibert, ${ }^{6,7}$ Virginie Pitiot, ${ }^{2}$ Matthieu Lahousse, ${ }^{8}$ \\ André Boibieux, ${ }^{8}$ Djamila Makhloufi, ${ }^{8}$ Chantal Simon, ${ }^{4,9}$ Muriel Rabilloud, ${ }^{10}$ \\ Mary Anne Trabaud, ${ }^{3}$ François Gueyffier, ${ }^{11}$ Jean-Baptiste Fassier, ${ }^{6,7}$ on behalf of \\ COVID-SER study group
}

To cite: Trouillet-Assant S Albert Vega C, Bal A, et al. Assessment of serological techniques for screening patients for COVID-19 (COVID-SER): a prospective, multicentric study. BMJ Open 2020;10:e041268. doi:10.1136/ bmjopen-2020-041268

- Prepublication history for this paper is available online. To view these files, please visit the journal online (http://dx.doi. org/10.1136/bmjopen-2020041268).

Received 03 June 2020 Revised 14 September 2020 Accepted 24 September 2020

D Check for updates

(c) Author(s) (or their employer(s)) 2020. Re-use permitted under CC BY-NC. No commercial re-use. See rights and permissions. Published by BMJ.

For numbered affiliations see end of article.

\section{Correspondence to} Dr Jean-Baptiste Fassier; jean-baptiste.fassier@chulyon.fr

\section{ABSTRACT}

Introduction The COVID-19 pandemic caused by SARSCoV-2 threatens global public health, and there is an urgent public health need to assess acquired immunity to SARS-CoV-2. Serological tests might provide results that can be complementary to or confirm suspected COVID-19 cases and reveal previous infection. The performance of serological assays (sensitivity and specificity) has to be evaluated before their use in the general population. The neutralisation capacity of the produced antibodies also has to be evaluated.

Methods and analysis We set up a prospective, multicentric clinical study to evaluate the performance of serological kits among a population of healthcare workers presenting mild symptoms suggestive of SARS-CoV-2 infection. Four hundred symptomatic healthcare workers will be included in the COVIDSER study. The values obtained from a control cohort included during the prepandemic time will be used as reference. A workflow was set up to study serological response to SARS-CoV-2 infection and to evaluate antibody neutralisation capacity in patients with a confirmed SARS-CoV-2 infection. The sensitivity and specificity of the tests will be assessed using molecular detection of the virus as a reference. The measurement of $\lg M$ and $\lg G$ antibodies will be performed once per week for 6 consecutive weeks and then at 6, 12, 18, 24 and 36 months after the diagnosis. The kinetics of $\mathrm{IgM}$ and $\mathrm{Ig} \mathrm{G}$ will determine the optimal period to perform serological testing. The proportion of false negative PCR tests in symptomatic subjects will be determined on the basis of subsequent seroconversions.

Ethics and dissemination Ethical approval has been obtained from the national review board for biomedical research in April 2020 (Comité de Protection des Personnes Sud Méditerranée I, Marseille, France) (ID RCB 2020-A00932-37). Results will be disseminated through presentations at scientific meetings and publications in peer-reviewed journals. Trial registration number NCT04341142.
Strengths and limitations of this study

- This study is a high-throughput evaluation of serological kits used to detect antibodies against SARS-CoV-2 in order to identify kits with the best performance.

- This is a prospective study designed to monitor the development of humoral response against SARS-CoV-2 infection in a population of healthcare workers.

- Long-term memory follow-up will be addressed up to 3 years postdiagnosis.

- Seroneutralisation techniques will assess acquired immunity against SARS-CoV-2.

- The study will assess the proportion of false negatives using the gold standard quantitative PCR in subjects with mild symptoms and with detected seroconversion.

\section{INTRODUCTION}

The COVID-19 outbreak that started in December 2019 has rapidly spread worldwide, and important efforts have been undertaken to contain the pandemic. The aetiological agent of COVID-19 was identified as related to severe acute respiratory syndrome coronavirus, known as SARS-CoV-2. Although the majority of SARS-CoV-2-infected individuals appear to have only mild to moderate symptoms, this virus is also responsible for severe and fatal cases. As of 25 August 2020, 813 207 deaths have been reported worldwide (https://coronavirus.jhu.edu/map.html). The development of immunity is important to reduce the transmission rate of SARS-CoV-2 and the associated mortality. ${ }^{1}$ There is an urgent public health need to assess acquired immunity to SARS-CoV-2. ${ }^{2}$ 
Serological assays, including binding assays such as ELISA or lateral flow assays, are essential tools in the management of infectious diseases, including diagnosis of infection, measurements of protective antibodies after vaccination and immunity assessment in a population. ${ }^{3}$ In addition, serological tests allow understanding of antibody responses after SARS-CoV-2 infection and evaluation of immune protection against reinfection. ${ }^{4}$ The duration of antibody response and the correlation of binding antibodies with virus neutralisation assay and with protection against reinfection are some of the questions that serological tests may be able to answer. ${ }^{5}$ Serological tests may have additional value in the management of patients with COVID-19 to confirm suspected cases or to reveal previous infection in cases of false negative PCR results. ${ }^{6}$ All of these elements are important to understanding the immunity conferred after infection and the immune status of the population against SARS-CoV-2. ${ }^{7}$ They may also allow workers at high risk of coronavirus exposure (such as in healthcare settings) to work safely knowing their immunity against the risk of reinfection. ${ }^{8}$

As there is an urgent need for a long-spectre testing method for SARS-CoV-2, an antigen-based system that meets the criteria of fast time-to-results and low-cost detection ${ }^{9}$ seems appropriate. However, the performance of serological kits has not been assessed. These tests might present heterogeneous sensitivity and specificity, ${ }^{10}$ and assessment of their performance is required in order to select a reliable kit to use in the population.

In brief, there are many uncertainties associated with serological testing. ${ }^{11}$ They are less efficient than reverse transcription PCR for diagnosis during the acute phase of the disease. Antibodies are detectable in a timedelayed manner, after the onset of symptoms, and their persistence over time is variable. Antibody kinetics have been studied mostly in hospitalised populations with signs of severity, but appear to be less rapid and with less amount of antibodies in populations with mild symptoms. Most notably, it is still unknown to what extent detectable antibodies imply immunity. ${ }^{11}$

\section{RATIONALE}

Acquired immunity to SARS-CoV-2 against reinfection still needs to be determined. Serological assays are required to measure the presence of SARS-CoV-2 antibodies and its correlation with immune protection. The COVID-SER project aims to assess the performance of different serological kits used to detect anti-SARS-CoV-2 antibodies and their neutralising capacity. The ultimate goal is to identify kits with higher performance in detecting IgM and IgG antibodies in order to measure the prevalence of SARS-CoV-2 infection and immunisation in the population. The detection of early IgM antibodies could be complementary to the PCR test used to diagnose the infection. It could allow a broader screening of symptomatic subjects. The later but sustained production of IgG antibodies could determine the immune protection of individuals against SARS-CoV-2.

\section{OBJECTIVES}

The objectives of the COVID-SER project are (1) to assess the performance of different serological kits in detecting anti-SARS-CoV-2 antibodies in a population of infected healthcare workers; (2) to monitor the development of humoral response against SARS-CoV-2 infection up to 36 months after diagnosis; (3) to evaluate the neutralising capacity of the antibodies produced; (4) to evaluate the false negative rate of the PCR tests; and (5) to assess the duration of the presence of SARS-CoV-2 in nasopharyngeal samples and its infectious potential.

\section{DELIVERABLES}

The objective is to identify the serological kits with the best performance in order to provide the population with a reliable and rapid screening tool. The expected collective benefit is to provide better understanding and management of the progression of the pandemic in the population.

\section{METHODS AND ANALYSIS}

The COVID-SER project is a prospective, longitudinal, multicentre clinical study conducted in a consortium of 13 university hospitals in Lyon, France (Hospices Civils de Lyon; 23000 workers; https://www.chu-lyon.fr/en).

\section{Study population}

COVID-SER will include healthcare workers $(\mathrm{N}=400)$ with symptoms suggestive of SARS-CoV-2 infection in whom a SARS-CoV-2 PCR test on a nasopharyngeal sample will be performed to diagnose the infection. The project is expected to include 130 positive subjects to meet the expected objectives. Participants must be over 18 years of age, provide informed consent and be affiliated to a social security system. The only criterion of exclusion is pregnancy or breast feeding, in accordance with French research regulations. Subjects have the right to withdraw from the study at any time if desired.

During March 2020, 30\%-50\% of symptomatic healthcare workers attending screening centres were tested PCR-positive for SARS-CoV-2 infection. Therefore, the initial period of inclusion was calculated up to 3 months, starting in April 2020, and the total duration of the study was initially expected to be 9 months. From 20 April 2020, amendments to the research protocol have been proposed to adapt to the evolution of the pandemic. The duration of inclusion was extended to 12 months, and the duration of follow-up (participation of each COVID-19positive subject) was extended to 36 months. The serum samples of healthy volunteers $(n=90)$ banked from a prepandemic period will be used as the reference negative cohort for the COVID-SER project. 


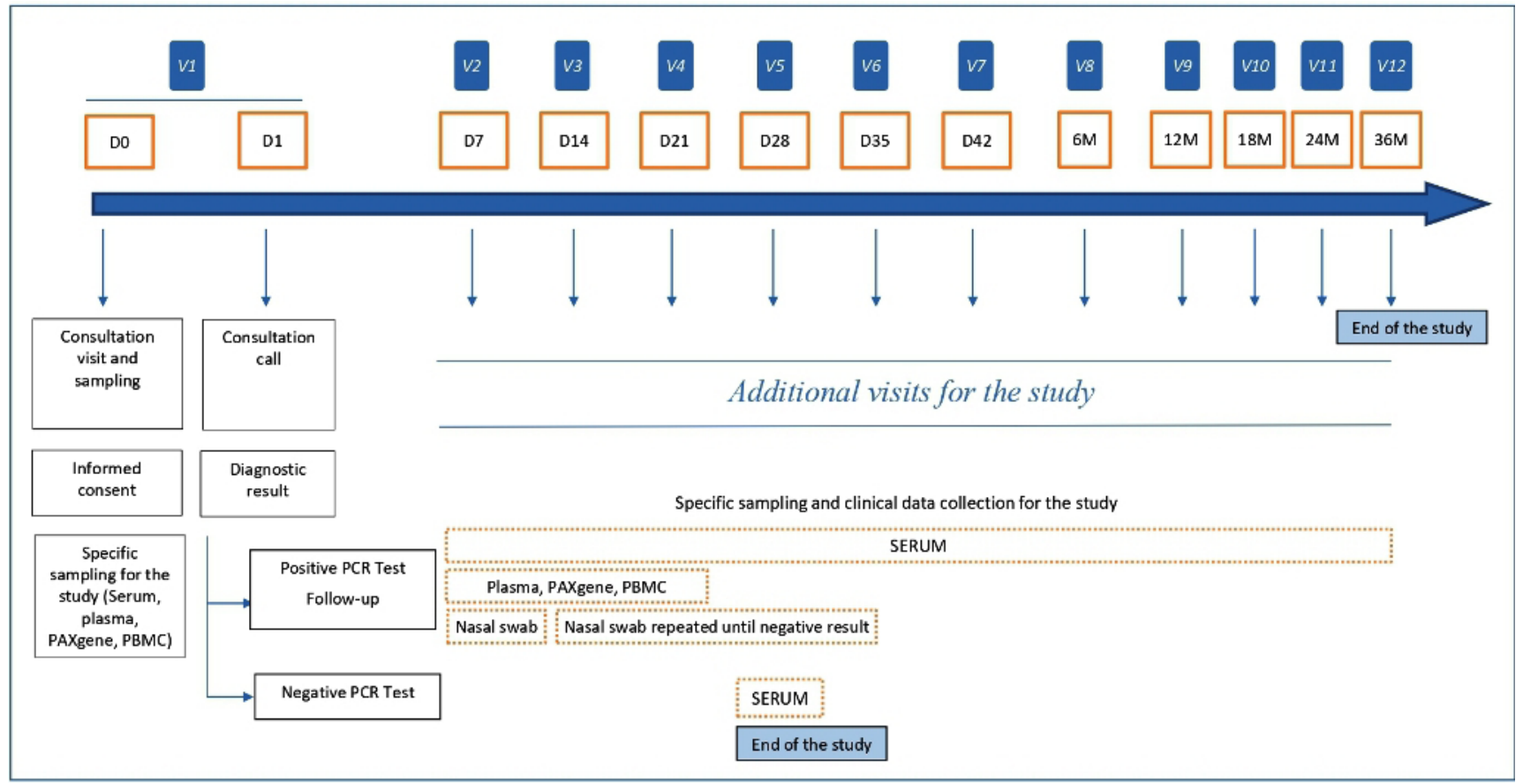

Figure 1 Schematic design of the COVID-SER project illustrating the various time points of the study and the type of collected sample at each visit. PBMC, peripheral blood mononuclear cell; V, visit.

\section{Sampling schedule}

At the first visit (V1), the study will be explained to the patient and the first sample will be taken. Patients with a positive PCR result at $\mathrm{V} 1$ will come back for the following visits: at day 7 (V2), 14 (V3), 21 (V4), 28 (V5), 35 (V6) and 42 (V7), and at 6, 12, 18, 24 and 36 months (V8V12) for serum samples. PCR tests will be performed at each visit until a negative result is obtained. Patients with a negative PCR result at V1 will come back only at day 28 (V5) for a serum sample. The sampling schedule is illustrated in figure 1 .

\section{Endpoints}

To address the objectives, the primary endpoint will be to assess the performance of the serological kits in detecting anti-SARS-CoV-2 antibodies in patients with symptoms (V1) and with positive PCR results. This will be done by evaluating the IgM and IgG production kinetics in the infected population during the additional visits (V2-V12) as well as the seroneutralisation capacity of the produced antibodies. The second endpoint will be to evaluate the PCR false negative rate in symptomatic subjects (V1) with negative PCR results compared with their serological response at V5.

\section{Biobanking}

If patient agrees to participate in the biocollection, a specific informed consent will be signed, and five types of blood samples will be collected, with additional $18.5 \mathrm{~mL}$ of blood per visit and patient. Refusal to participate in the biocollection does not compromise participation in the study and only $8 \mathrm{~mL}$ of blood will be collected. This study will provide the opportunity to establish a biobank, enabling further exploration of innovative biomarkers: (1) EDTA plasma biobank to study viral reactivation markers and soluble host biomarkers; (2) peripheral blood mononuclear cell isolated from the blood collected in EDTA tube; and (3) RNA biobank to study new transcriptomic host biomarkers (RNA will be extracted from whole blood collected in PAXgene tubes).

\section{Serological tests}

A description of the serological tests to be evaluated in the study is shown in table 1.

\section{Antibody titre assessment}

Titres will be assessed as recommended by the manufacturers and described in table 1.

Virus neutralisation assay

A 10-fold dilution of each serum specimen in Dulbecco modified Eagle medium containing antibiotics and 2\% fetal calf serum will first be heated for $30 \mathrm{~min}$ at $56^{\circ} \mathrm{C}$ in order to avoid complement-linked reduction of viral activity. The virus to be used in these experiments (RoBo strain) will be a clinical strain isolated on VERO-E6 cells from a patient hospitalised at the University Hospital of Saint-Etienne for severe COVID-19 infection; it will be diluted in the same medium to obtain 100-500 tissue culture infectious doses at $50 \%$ (TCID50) per $150 \mu \mathrm{L}$. Virus infectivity controls will be included in each test. Serial twofold dilutions (tested in duplicate) of the specimens will be mixed with the diluted virus at equal volume $(100 \mu \mathrm{L}$ each). After gentle shaking and a contact of $30 \mathrm{~min}$ at room temperature in plastic microplates, $150 \mu \mathrm{L}$ of the mix will be transferred to 96-well microplates 
Table 1 Description of the serological tests to be evaluated in the study

\begin{tabular}{|c|c|c|c|c|}
\hline Manufacturer & System & Product & Principle & Titre assessment \\
\hline Abbott & ARCHITECT & SARS-CoV-2 lgG & CMIA & Index: sample/calibrator RLU \\
\hline bioMérieux & VIDAS & $\begin{array}{l}\text { VIDAS SARS-CoV-2 IgG } \\
\text { VIDAS SARS-CoV-2 IgM }\end{array}$ & ELFA & Ratio: patient RFV/standard RFV \\
\hline Bio-Rad & $\begin{array}{l}\text { Manual or automated } \\
\text { ELISA systems }\end{array}$ & Platelia SARS-CoV-2 Total Ab & ELISA & $\begin{array}{l}\text { Ratio: sample OD/mean cut-off control } \\
\text { OD }\end{array}$ \\
\hline DiaSorin & LIAISON XL & LIAISON SARS-CoV-2 S1/S2 IgG & CLIA & $\mathrm{AU} / \mathrm{mL}$ \\
\hline Siemens & Atellica IM & SARS-CoV-2 Total & CLIA & Index: sample/calibrator RLU \\
\hline Wantai & $\begin{array}{l}\text { Manual or automated } \\
\text { ELISA systems }\end{array}$ & $\begin{array}{l}\text { WANTAI SARS-CoV-2 Ab ELISA } \\
\text { WANTAI SARS-CoV-2 IgM ELISA }\end{array}$ & ELISA & Ratio: sample OD/cut-off OD \\
\hline AAZ & None & $\begin{array}{l}\text { COVID-PRESTO (RT COVID-19 lgG/ } \\
\text { IgM) }\end{array}$ & LFIA & Qualitative \\
\hline
\end{tabular}

AU, arbitrary unit; CLIA, chemiluminescence luminescence immuno assay; CMIA, chemiluminescence microparticle luminescence immunoassay; ELFA, enzyme linked fluorescence assay; LFIA, lateral flow immunochromatographic assay; OD, optical density; RFV, relative fluorescence value; $R L U$, relative light unit.

covered with VERO-E6 cells. The plates will be placed at $37^{\circ} \mathrm{C}$ in a $5 \% \mathrm{CO}_{2}$ incubator. The reading will be evaluated microscopically 5-6 days later when the cytopathic effect of the virus control reaches 100 TCID $50 / 150 \mu \mathrm{L}$. A seroprotection will be recorded if more than $50 \%$ of the cells are preserved. The protection titre will be expressed as the inverse of the higher serum dilution that spared the cells. The threshold of positivity for protective antibodies will be 10 . All the experiments will be performed in an L3 facility.

\section{Sample size and data analysis plan \\ Study design and sample size}

A prospective cohort of healthcare workers will be used to assess the sensitivity of different serological tests in detecting SARS-CoV-2 antibodies and to monitor the IgG and IgM kinetics. Serum samples from healthy volunteers $(n=90)$ banked from a prepandemic period will be used to assess the specificity of the serological tests. The inclusion of 130 PCR-positive healthcare workers at V1 will provide $80 \%$ power to detect a sensitivity higher than $70 \%$, and the inclusion of serum samples from 90 healthy volunteers will provide $80 \%$ power to detect a specificity higher than $80 \%$. The number of subjects required to determine the expected threshold for the serological kits tested was defined using the function binDesign (binGroup package, 'R' software) and the Wilson methodology to build the confidence range.

\section{Statistical methods}

The characteristics of the positive and negative PCR samples will be described and quantified as median (IQR). To evaluate the primary endpoint, the sensitivity of the different serological tests in the infected population will be assessed according to the threshold established by the manufacturers, with CI obtained by the Wilson method. The specificity of the serological tests will be assessed by the same method on the healthy serum samples. The sensitivity and specificity of the different serological kits will be compared using McNemar test. The sensitivity of the best performing kits will be modelled through logistic regression to quantify the delay on the quantification of antibodies from the beginning of the symptoms or a specific therapy. Factors acting on the sensibility will be quantified as OR $(95 \% \mathrm{CI})$. To evaluate the evolution of antibody production (IgM and IgG), a mixed-effects linear regression will be modelled. Antibody production will be assessed by optical density ratios determined according to the manufacturer's recommendation. Analyses will be conducted with the latest version of ' $R$ ' software.

\section{Ethics and dissemination}

Ethics approval

The study is registered with the French Commission for Individual Data Protection and Public Liberties (CNIL) of Lyon's University Hospital (number 20-120). Ethical approval has been obtained from the national review board for biomedical research in April 2020 (Comité de Protection des Personnes Sud Méditerranée I, Marseille, France) (ID RCB 2020-A00932-37).

\section{Informed consent}

The subjects included in the study will be kept anonymous and their identification protected by a cryptographic code. Data will be anonymously extracted from medical records (HCL Software). Informed and signed consent will be registered on the computerised record of each subject. Full information of the objectives and the workflow of the study will be provided and the possibility of refusal to participate or to withdraw from the study 
whenever they choose will be explained to the subjects. A comprehensive notice summarising the protocol and study follow-up will be distributed to the subjects. Participants will be informed at the time of inclusion in the study that the interpretation of results is limited by the current state of knowledge and that a positive serological test does not mean that they are immune to the virus.

\section{Dissemination}

Results will be communicated at scientific meetings and submitted for publication in peer-reviewed journals.

\section{Safety of participants}

This study includes no serious foreseeable risk to the health of the subjects involved. The only potential risk is related to blood sample collection (maximum of $212 \mathrm{~mL}$ collected over all time points-6 months). However, this aspect of nursing is part of daily practice. Blood samples will be taken under the same safety conditions as currently used for common diagnostic tests.

\section{Patient and public involvement}

No patient was involved in the design or implementation of this study. Study participants will be individually informed about their results during scheduled medical visits and will be given access, on demand, to the final publication of the study results.

\section{Author affiliations}

${ }^{1}$ Virpath - Université Lyon, CIRI, INSERM U1111, CNRS 5308, ENS, UCBL, Faculté de Médecine Lyon Est, Lyon, France

${ }^{2}$ Hospices Civils de Lyon, Centre Hospitalier Lyon Sud, Pierre Benite, France

${ }^{3}$ Laboratoire de Virologie, Institut des Agents Infectieux (IAI), Hospices Civils de Lyon, Groupement Hospitalier Nord, Lyon, France

${ }^{4}$ CRNH Rhône-Alpes, University Lyon 1, Laboratoire CarMeN, Inserm U1060, INRA

U1397, Pierre Benite, France

${ }^{5}$ Centre d'appui à la Prévention des Infections Associées aux Soins Auvergne Rhône-Alpes, Hospices Civils de Lyon - Hôpital H Gabrielle, 20 route de Vourles, Saint Genis Laval, France

${ }^{6}$ UMR T 9405, Univ Lyon, Univ Eiffel, Univ Lyon 1, IFSTTAR, UMRESTTE, Lyon, France ${ }^{7}$ Service de médecine du travail et des pathologies professionnelles, Hospices Civils de Lyon, Centre Hospitalier Lyon Sud, Pierre Benite, France

${ }^{8}$ Infectious and Tropical Diseases Unit, Hospices Civils de Lyon, Edouard Herriot Hospital, Lyon, France

${ }^{9}$ Service d'Endocrinologie, diabète, nutrition, Hospices Civils de Lyon, Centre Hospitalier Lyon Sud, Pierre Benite, France

${ }^{10}$ Université de Lyon; Université Lyon 1; Hospices Civils de Lyon, Pôle Santé Publique, Service de Biostatistique et Bioinformatique ; CNRS, UMR 5558, Laboratoire de Biométrie et Biologie Évolutive, Équipe Biostatistique-Santé, Lyon, France

${ }^{11}$ UMR5558, Service des Données de Santé, Pôle de Santé Publique, Hospices Civils de Lyon, \& Université de Lyon, Université Lyon 1, CNRS, Laboratoire de Biométrie et Biologie Evolutive, Villeurbanne, France

Acknowledgements We thank HCL COVID-19 Task Force for their helpful advice, as well as the Hospices Civils de Lyon and the Fondation des Hospices Civils de Lyon for their support.
Collaborators COVID-SER study group: Adnot Jérôme, Alfaiate Dulce, Bal Antonin, Bergeret Alain, Boibieux André, Bonnet Florent, Bourgeois Gaëlle, Brunel-Dalmas Florence, Caire Eurydice, Charbotel Barbara, Chiarello Pierre, Cotte Laurent, d'Aubarede Constance, Durupt François, Escuret Vanessa, Fascia Pascal, Fassier Jean-Baptiste, Fontaine Juliette, Gaillot-Durand Lucie, Gaymard Alexandre, Gillet Myriam, Godinot Matthieu, Gueyffier François, Guibert Nicolas, Josset Laurence, Lahousse Matthieu, Lina Bruno, Lozano Hélène, Makhloufi Djamila, MassardierPilonchéry Amélie, Milon Marie-Paule, Moll Frédéric, Morfin Florence, Narbey David, Nazare Julie-Anne, Oria Fatima, Paul Adèle, Perry Marielle, Pitiot Virginie, Prudent Mélanie, Rabilloud Muriel, Samperiz Audrey, Schlienger Isabelle, Simon Chantal, Trabaud Mary-Anne, Trouillet-Assant Sophie.

Contributors ST-A, AB, JAN, PF, AP, AM-P, CdA, NG, VP, ML, AB, DM, CS, MR, MAT, $\mathrm{FG}$ and J-BF were involved in trial design. ST-A, CAV, $A B$ and J-BF were involved in drafting of the manuscript. All authors were involved in critical revision of the article for important intellectual content and approved the final version.

Funding The authors have not declared a specific grant for this research from any funding agency in the public, commercial or not-for-profit sectors.

Competing interests $A B$ has received grant from bioMérieux and has served as consultant for bioMérieux for work and research not related to this manuscript.

Patient and public involvement Patients and/or the public were not involved in the design, or conduct, or reporting, or dissemination plans of this research.

Patient consent for publication Not required.

Provenance and peer review Not commissioned; externally peer reviewed.

Open access This is an open access article distributed in accordance with the Creative Commons Attribution Non Commercial (CC BY-NC 4.0) license, which permits others to distribute, remix, adapt, build upon this work non-commercially, and license their derivative works on different terms, provided the original work is properly cited, appropriate credit is given, any changes made indicated, and the use is non-commercial. See: http://creativecommons.org/licenses/by-nc/4.0/.

ORCID iD

Chloe Albert Vega http://orcid.org/0000-0002-5914-3554

\section{REFERENCES}

1 Winter AK, Hegde ST. The important role of serology for COVID-19 control. Lancet Infect Dis 2020;20:758-9.

2 Wu F, Wang A, Liu M, et al. Neutralizing antibody responses to SARS-CoV-2 in a COVID-19 recovered patient cohort and their implications. medRxiv 2020.

3 Lee CY-P, Lin RTP, Renia L, et al. Serological approaches for COVID-19: epidemiologic perspective on surveillance and control. Front Immunol 2020;11:879.

4 Sethuraman N, Jeremiah SS, Ryo A. Interpreting diagnostic tests for SARS-CoV-2. JAMA 2020;323:2249-51.

5 Krammer F, Simon V. Serology assays to manage COVID-19. Science 2020;368:1060-1.

6 Tang Y-W, Schmitz JE, Persing DH, et al. Laboratory diagnosis of COVID-19: current issues and challenges. J Clin Microbiol 2020;58.

7 Abbasi J. The promise and peril of antibody testing for COVID-19. JAMA 2020;323:1881-3.

8 Amanat F, Stadlbauer D, Strohmeier S, et al. A serological assay to detect SARS-CoV-2 seroconversion in humans. medRxiv 2020:20037713.

9 Venter M, Richter K. Towards effective diagnostic assays for COVID-19: a review. J Clin Pathol 2020;73:370-7.

10 Zainol Rashid Z, Othman SN, Abdul Samat MN, et al. Diagnostic performance of COVID-19 serology assays. Malays $J$ Pathol 2020;42:13-21.

11 Deeks JJ, Dinnes J, Takwoingi Y, et al. Antibody tests for identification of current and past infection with SARS-CoV-2. Cochrane Database Syst Rev 2020;6:Cd013652. 